\title{
HEPATITIS
}

\section{Suppression of haematopoiesis during therapy of chronic hepatitis $C$ with different interferon $\alpha$ mono and combination therapy regimens}

\author{
M Schmid, A Kreil, W Jessner, M Homoncik, C Datz, A Gangl, P Ferenci, M Peck-Radosavlievic
}

Gut 2005;54:1014-1020. doi: 10.1136/gut.2004.057893

\begin{abstract}
See end of article for authors' affiliations

......................

Correspondence to: Dr M Peck-Radosarljevic, Department of Internal Medicine IV, Division of Gastroenterology and Hepatology, University of Vienna, Währingergürtel 18-20, A-1090 Vienna Austria; markus.peck@ meduniwien.ac.at
\end{abstract}

Revised version received 8 February 2005 Accepted for publication 9 March 2005
Background: Treatment of chronic hepatitis $C$ with interferon (IFN)- $\alpha$ and ribavirin has haematotoxic effects. We evaluated the effects of four different IFN/IFN-ribavirin treatment regimens on haematopoiesis.

Methods: Haematopoiesis was studied in 133 patients with chronic hepatitis $C$ receiving IFN- $\alpha 2 b$ alone (group A) or in combination with ribavirin (group B), pegylated IFN- $\alpha 2 a$ (group C), or pegylated IFN- $\alpha 2 b$ (group D) in combination with ribavirin.

Results: At week 4, haemoglobin levels were diminished in all groups receiving combination therapy. In the monotherapy group, haemoglobin decreased slightly after eight weeks. In all groups, haemoglobin remained diminished throughout therapy. In all patients, leucocytes (while blood cells) decreased after four weeks and remained low during treatment. Platelets (peripheral platelet count (PPC)) were decreased in all groups after four weeks and remained below baseline levels during therapy in group $A, C$, and D whereas in group B PPC recovered early and reached baseline levels at week 16 of therapy. Concomitantly with the decreases in haemoglobin and PPC, erythropoietin increased in all groups receiving combination therapy and thrombopoietin in all groups. Patients treated with pegylated IFN- $\alpha 2$ a and those who received pegylated IFN- $\alpha 2 b$ combination therapy differed only in leucopoiesis, whereas erythropoiesis and thrombopoiesis were comparable.

Conclusion: IFN- $\alpha$ based therapies are associated with a decrease in all three haematopoietic lineages, irrespective of the type of therapy used. The stronger suppressive effect of pegylated IFN- $\alpha 2 a$ on leucopoiesis could be due to a dose effect. Overall, concentrations of endogenous haematopoietic growth factors are increased but can only partially alleviate haematotoxicity. Potential uses of exogenous haematopoietic growth factors and their impact on the virological response need to be explored.
C hronic hepatitis $\mathrm{C}$ is a major cause of cirrhosis, end stage liver disease, and hepatocellular carcinoma. ${ }^{1-3}$ The current treatment of choice for chronic hepatitis $\mathrm{C}$ is combination therapy with interferon $\alpha$ (IFN- $\alpha$ ) and ribavirin (RBV). ${ }^{4}$ Unfortunately, both drugs have significant haematological toxic effects. ${ }^{6-8}$

IFN- $\alpha$ exerts antiproliferative effects on many cell types. These properties are used for treatment of chronic myeloproliferative and lymphoproliferative diseases $^{910}$ but also account for several undesirable effects, such as thrombocytopenia and leucopenia, and can interfere with the successful clinical application of full dose IFN- $\alpha$ in patients with chronic hepatitis C. ${ }^{11}$

IFN induced thrombocytopenia and leucopenia is common whereas anaemia is more a sequela of combination therapy with ribavirin. ${ }^{451213}$ Thrombocytopenia is mild in most cases, amounting to a decrease in peripheral platelet count of $10-50 \%$ but, when severe, can lead to bleeding complications $^{14}{ }^{15}$ and discontinuation of IFN therapy. ${ }^{16}$ Absolute neutrophil and lymphocyte counts typically decrease by $30-$ $50 \%$ of baseline values during IFN therapy but this is usually not associated with infection. ${ }^{17} 18$

The main mechanism leading to cytopenia during IFN therapy seems to be bone marrow suppression by IFN- $\alpha{ }^{19-21}$ This suppressive action can be observed for pluripotent progenitor cells of all lineages. ${ }^{19}{ }^{20}$ Immune mediated haematological toxicity ${ }^{21}$ and capillary sequestration of platelets and white blood cells ${ }^{22}$ have been proposed as additional causes for severe thrombocytopenia and leucopenia during IFN therapy.
Ribavirin treatment causes varying degrees of anaemia, presumably through haemolysis. ${ }^{12} 1323$ Discontinuation of IFN therapy usually leads to restitution of a normal complete blood count within several weeks. ${ }^{58}$ Dose reductions can improve haematological toxicities but carry the risk of a suboptimal treatment response. ${ }^{24}$

To develop treatment strategies to improve adherence to IFN/RBV therapy, we studied the long term effects of IFN monotherapy and three different IFN/ RBV treatment regimens on the corpuscular elements of the blood, and on growth factors for thrombopoiesis and erythropoiesis in patients on antiviral therapy for chronic hepatitis C.

\section{MATERIALS AND METHODS}

\section{Patients}

A total of 133 patients with chronic hepatitis C participating in six prospective trials (table 1 ) with conventional IFN- $\alpha 2 \mathrm{~b}$ (IntronA; Aesca-Schering Plough, Traiskirchen, Austria), pegylated IFN- $\alpha 2$ a (PEGASYS; Roche, Vienna, Austria), or pegylated IFN- $\alpha 2 b$ (PegIntron; Schering-Plough, Kenilworth, New Jersey, USA) alone or in combination with ribavirin (Rebetol; Aesca-Schering Plough, Traiskirchen, Austria) were studied. Patient characteristics are shown in table 2.

Abbreviations: $\mathrm{HCV}$, hepatitis $\mathrm{C}$ virus; IFN- $\alpha$, interferon $\alpha$; RBV, ribavirin; WBC, white blood count; PPC, peripheral platelet count; EPO, erythropoietin; TPO, thrombopoietin; TIW, three times a week; BW, body weight; ANOVA, analysis of variance for repeated measurements; pegIFN, pegylated interferon; SOCS-1, suppressor of cytokine signalling 1 


\begin{tabular}{|c|c|c|c|c|c|}
\hline Group & Interferon type and dose & $\begin{array}{l}\text { Ribavirin dose } \\
\text { (mg/day) }\end{array}$ & $\begin{array}{l}\text { Duration of therapy } \\
\text { (weeks) }\end{array}$ & $\mathbf{n}$ & Reference \\
\hline A & $5 \mathrm{MU}$ IFN- $\alpha 2 \mathrm{~b}$ TIW & - & 36 & 26 & $\begin{array}{l}\text { (Datz C, unpublished data), } \\
\text { Ferenci }\end{array}$ \\
\hline B & $5 \mathrm{MU}$ IFN- $\alpha 2 \mathrm{~b}$ TIW & $1000-1200$ & 38 & 32 & Ferenci $^{26}$ \\
\hline C & $\begin{array}{l}180 \mu \mathrm{g} 40 \mathrm{kDa} \text { pegylated } \\
\text { IFN- } \alpha 2 \mathrm{a} / \text { week }\end{array}$ & $1000-1200$ & 48 & 41 & $\begin{array}{l}\text { (Ferenci P, unpublished data), } \\
\text { Fried }^{27}\end{array}$ \\
\hline D & $\begin{array}{l}1.5 \mu \mathrm{g} / \mathrm{kg} 12 \mathrm{kDa} \text { pegylated } \\
\text { IFN- } \alpha 2 \mathrm{~b} / \text { week }\end{array}$ & $1000-1200$ & 24 & 34 & (Ferenci $P$, unpublished data) \\
\hline
\end{tabular}

The protocols conformed to the ethical guidelines of the 1975 Declaration of Helsinki in its most recent form and were approved by the institutional review committee of the University of Vienna Medical Faculty. Informed written consent was obtained from each patient before entry into the study.

Blood for measurements of all parameters was obtained on day 0 (before IFN therapy), and at weeks 4, 8,12, 16, 20, 24 (all groups), 36 (groups A, B, and C), and 48 (only group C) after beginning IFN therapy. All patients were followed up one and six months after the end of IFN therapy.

\section{Measurements}

Hepatitis C viral load was determined by Cobas Amplicor HCV Monitor version 2.0 (Roche Diagnostics, Branchburg, New Jersey, USA).

Prothrombin time was measured as a percentage of a reference sample to account for variabilities in absolute values (seconds) between batches of reagents ("Normotest"; normal range $75-120 \%$ ) which has been shown to be the most reliable test of global coagulation in liver disease. ${ }^{30}$

\section{TPO enzyme linked immunosorbent assay and EPO enzyme linked immunosorbent assay}

Serum levels of thrombopoietin (TPO) and erythropoietin (EPO) were measured using the Quantikine human TPO and EPO enzyme linked immunosorbent assay (ELISA; R\&D Systems, Abingdon, UK). Both assays were performed according to the manufacturer's instructions, as previously described. ${ }^{81}$

\section{Statistical analysis}

Statistical analysis was performed using STATISTICA for Windows v.5.1 (Statsoft Inc., Hamburg, Germany). The Wilcoxon matched pairs test was used for within patient comparisons between pre-IFN therapy values and individual time points during therapy. Differences between different patient groups were analysed using the Mann-Whitney U test. A p value $<0.05$ was considered statistically significant.

\section{RESULTS}

\section{Erythropoiesis during IFN therapy}

After four weeks of IFN- $\alpha$ therapy, haemoglobin levels decreased in the patient groups receiving combination therapy (median values: group B, $10 \%$; group C, $20 \%$; group D, $13 \% ; p<0.001$ ) but not in patients receiving monotherapy. After eight weeks, haemoglobin levels decreased slightly in patients receiving monotherapy (group A, $5 \%$; $<0.05$ ) (fig 1 , table 3). In the following weeks of treatment haemoglobin levels remained below baseline in all groups, with a maximum decrease of $5 \%$ in group A at weeks 12 and 20 , $16 \%$ in group B at week $20,22 \%$ in group C at week 48 , and $19 \%$ in group D at weeks 16 and 20 (fig 1, table 3). In the first 24 weeks of therapy (duration of therapy in group D), a haemoglobin level below $11 \mathrm{~g} / \mathrm{dl}$ occurred in 15\%, 38\%, 46\%, and $44 \%$ of patients in groups $\mathrm{A}, \mathrm{B}, \mathrm{C}$, and $\mathrm{D}$, respectively (group A $v$ group C, group A $v$ group $\mathrm{D}, \mathrm{p}<0.05$; group $\mathrm{A} v$ group $\mathrm{B}$, group $\mathrm{B} v$ group $\mathrm{C}$, group $\mathrm{B} v$ group $\mathrm{D}$, group $\mathrm{C} v$ group D, NS) and a decline in haemoglobin below $10 \mathrm{~g} / \mathrm{dl}$ was found in $6 \%$ of patients in group B, in $29 \%$ in group C, and in $15 \%$ in group D (group B $v$ group $\mathrm{C}, \mathrm{p}<0.05$; group $\mathrm{B} v$ group $\mathrm{D}$, group C $v$ group $\mathrm{D}, \mathrm{NS})$.

In six patients in group B (19\%), 15 patients in group C $(37 \%)$, and 10 patients in group D (29\%) the ribavirin dose was reduced (group B $v$ group C, group B $v$ group D, group C $v$ group D, NS). Two patients in group $B, 11$ patients in group $\mathrm{C}$, and four patients of group D received less than $80 \%$ of their scheduled dose of RBV (group B $v$ group $\mathrm{C}, \mathrm{p}<0.05$; group B $v$ group D, group C $v$ group D, NS). Consequently, patients in group B received an average of $99 \%$ of the planned dosage (1054 (633-1200) $\mathrm{mg}$ of $1069(800-1200) \mathrm{mg})$, patients in group C received 94\% (1041 (358-1200) mg of 1112 (8001200) $\mathrm{mg}$ ), and patients in group D received $96 \%$ of the anticipated dose (980 (508-1200) mg of $1024 \quad(800-$ 1200) $\mathrm{mg}$ ) over the whole therapy period. Haemoglobin did not decrease below $8.5 \mathrm{~g} / \mathrm{dl}$ in any patient.

After termination of treatment, haemoglobin levels increased rapidly and returned to baseline after four weeks in group A and after 24 weeks in group B. In groups C and D,

Table 2 Patient characteristics

\begin{tabular}{|c|c|c|c|c|}
\hline & Group A & Group B & Group C & Group D \\
\hline $\operatorname{Sex}(M / F)$ & $5 / 1$ & $23 / 9$ & $24 / 17$ & $18 / 16$ \\
\hline & (9-65) & 37 & 44 & 4) \\
\hline Weight $(\mathrm{kg})$ & $79(51-92)$ & $72(50-95)$ & $78(51-103)$ & $72(48-100)$ \\
\hline$H^{2}$ subtype $^{28 *}(1 a / 1 b / 2 / 3 / 4)$ & $2 / 7 / 2 / 6 / 0+$ & $7 / 9 / 0 / 9 / 3+$ & $14 / 25 / 0 / 1 / 1 \dagger$ & $5 / 16 / 2 / 14 / 0 \dagger$ \\
\hline Viral load pre-IFN (IU $\left.\times 10^{3} / \mathrm{ml}\right)$ & & $1052(94-7880)$ & $2848(83-8500)$ & $1300(84-7800)$ \\
\hline Fibrosis stage $^{29 *}(\mathrm{I} / \mathrm{II} / \mathrm{III} / \mathrm{IV})$ & $5 / 7 / 3 / 6 \S$ & $2 / 19 / 5 / 2 \S$ & $2 / 20 / 4 / 10 \S$ & $3 / 20 / 3 / 8$ \\
\hline
\end{tabular}

*References for the relevant staging/scoring system.

†Patients coinfected with different hepatitis $C$ virus (HCV) genotypes (group $A$, one; group B, two; group $C$, three; group $D$, three).

$\ddagger$ No data available for group $A$.

§No biopsy obtained (group A, five; group B, four; group C, five). 

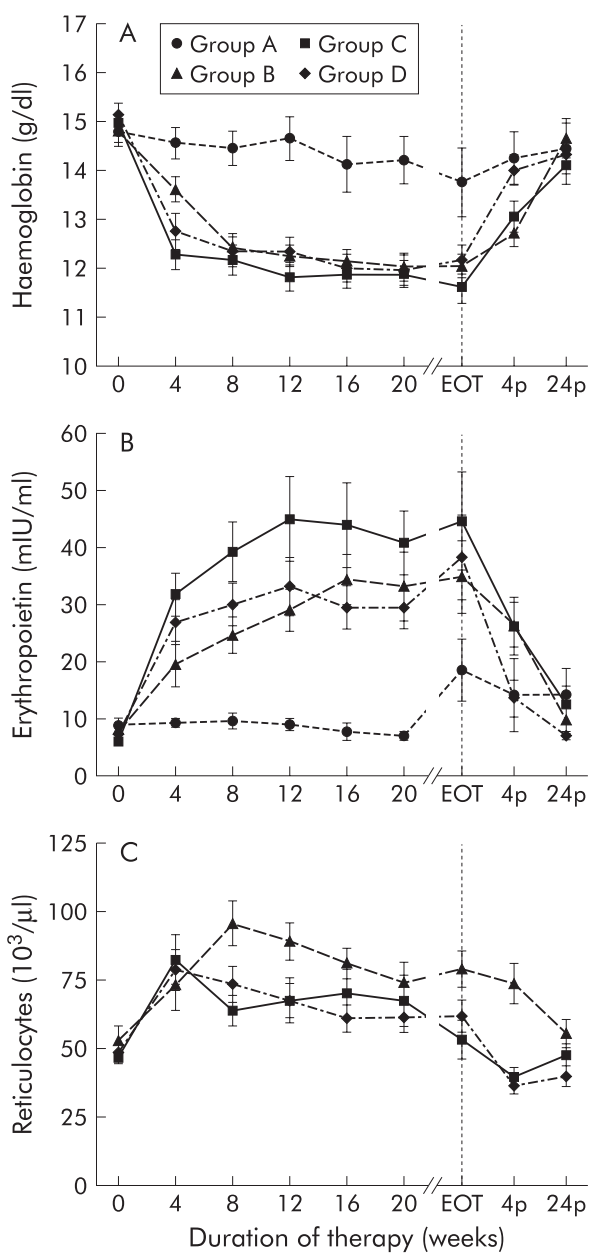

Figure 1 Erythropoiesis. Haemoglobin level (A), erythropoietin level (B), and reticulocyte count (C) before (week 0), during (week 4 until the end of therapy (EOT)) and after (week $4 p$ and week 24p) therapy with conventional interferon $\alpha$ (IFN- $\alpha$ ) alone (group $A)$, in combination with ribavirin (group B), with pegylated IFN- $\alpha 2$ a (group C), or with pegylated IFN- $\alpha 2 b$ in combination with ribavirin (group D). Data are mean (SEM).

haemoglobin levels also increased significantly after discontinuation of therapy but did not reach baseline levels within the study period (group C, 4\%; group D, 3\% below baseline at week 24 after therapy) (fig 1, table 3). As expected, the decrease in haemoglobin levels was more severe in patients receiving combination therapy with $\mathrm{RBV}$ than in those receiving IFN- $\alpha$ alone (group A $v$ group B, group A $v$ group C, group A $v$ group $\mathrm{D}, \mathrm{p}<0.05$ at any week of therapy) (fig $\mathrm{l}$ ). Patients in groups B, C, and D showed comparable decreases in haemoglobin levels with significant differences only at the beginning of therapy (group B $v$ group C, group B $v$ group D, $\mathrm{p}<0.05$ at week 4 , NS at any other week of therapy; group $\mathrm{C} v$ group D, NS at any week of therapy; fig 1).

EPO levels increased by a median of $9 \%$ in group A $(p=0.5), 119 \%$ in group $B(p<0.001), 385 \%$ in group $C$ $(\mathrm{p}<0.0001)$, and $272 \%$ in group $\mathrm{D}(\mathrm{p}<0.0001)$ at week 4 (fig 1, table 3). Within the next weeks of therapy, EPO levels further increased in patients receiving combination therapy $(\mathrm{p}<0.001$ for any week of therapy), group B reaching maximum EPO levels at week 16 (median increase 520\%, $\mathrm{p}<0.001$ ), group $\mathrm{C}$ at week 20 (median increase 543\%, $\mathrm{p}<0.0001$ ), and group D at week 24 (median increase 353\%, $\mathrm{p}<0.0001)$. In the groups receiving combination therapy, EPO levels remained significantly above baseline values throughout the whole therapy. In group A, receiving IFN- $\alpha$ alone, EPO levels increased significantly only at the end of treatment (median increase in group A, $131 \%$; p $<0.05$ at week 36). After discontinuation of therapy, EPO levels returned to baseline within four weeks in groups $\mathrm{A}$ and $\mathrm{D}$ and within 24 weeks in group B, while in group C EPO levels were still elevated at the end of follow up (group C: $65 \%$ above baseline at week 24 after the end of therapy) (fig 1, table 3).

EPO levels differed between patients receiving combination therapy or monotherapy (group A $v$ group $\mathrm{B}, \mathrm{p}<0.05$ for weeks 8 to end of therapy; group A $v$ group C, group A $v$ group $\mathrm{D}, \mathrm{p}<0.05$ for any week of therapy) Except at week 4 , the increase in EPO levels was similar in patients on combination therapy (group B $v$ group C, group B $v$ group $\mathrm{D}, \mathrm{p}<0.05$ at week 4, NS at any other week of therapy; group $\mathrm{C} v$ group D, NS at any week of therapy (fig 1).

The reticulocyte count as a measure of bone marrow regenerative activity of erythroid progenitor cells was increased after four weeks of treatment in groups B, C, and D (median increase in group $\mathrm{B}, 41 \%$; group C, $58 \%$; group D, $45 \% ; \mathrm{p}<0.01$ ) (fig 1 , table 3 ). In patients in group $\mathrm{C}$, the reticulocyte count decreased again after week 4 reaching baseline levels at week 24 of therapy despite continuously decreased haemoglobin levels and markedly compensatory increases in EPO levels, whereas in patients in groups B and $D$ the reticulocyte count remained elevated compared with baseline values throughout the therapy (group $\mathrm{B}, \mathrm{p}<0.001$; group $\mathrm{D}, \mathrm{p}<0.05$ for any week of therapy) with a maximum increase of $102 \%$ at week 12 in group B and $45 \%$ at week 4 in group D. Reticulocyte count in groups B and D returned to baseline at week 24 after the end of treatment (fig 1, table 3). Starting at week 8, patients in group B showed significantly higher levels of reticulocytes than those of groups C and D (Mann-Whitney $U$ test: $p<0.05$ for week 8 until the end of therapy) (fig 1). Patients with or without liver cirrhosis did not differ in their erythropoietic response to IFN mono or combination therapy (NS).

\section{Thrombopoiesis during IFN therapy}

At week 4 of therapy, peripheral platelet count (PPC) decreased in all groups (median decrease in group A, 25\%; group B, $8 \%$; group C, $21 \%$; group D, $23 \%$; $p<0.05$ for all groups) (fig 2, table 3). In group B, PPC increased again after week 12, reaching baseline values at week 16, and remained above baseline levels until the end of therapy. In the other three groups, PPC remained decreased throughout therapy, with a nadir of $34 \%$ in group A at week $16,36 \%$ in group $C$ at week 8 , and $24 \%$ in group D at week 12 . Platelets returned to baseline levels within four weeks after discontinuation of therapy in these groups (fig 2, table 3 ). The decrease in PPC was comparable between groups A, C, and D (Mann-Whitney U test: NS throughout therapy), and groups B and D (group B $v$ group $\mathrm{D}, \mathrm{p}<0.05$ at week 20, NS for any other week of therapy). Patients in group B showed significantly higher PPC levels than those of groups A and C (group A $v$ group B, $\mathrm{p}<0.05$ for weeks 4-20; group C $v$ group $\mathrm{B}, \mathrm{p}<0.05$ for week 8 to end of therapy) (fig 2).

After four weeks of treatment, thrombopoietin (TPO) levels increased by a median of $32 \%, 2 \%, 49 \%$, and $48 \%$ in group A $(\mathrm{p}<0.001)$, group $\mathrm{B}(\mathrm{p}<0.05)$, group $\mathrm{C}(\mathrm{p}<0.0001)$, and group $\mathrm{D}(\mathrm{p}<0.001)$, respectively (fig 2 , table 3$)$. Within the next weeks of therapy, TPO levels further increased in all groups, reaching maximum levels at the end of therapy (median increase in group A, $58 \%, \mathrm{p}<0.05$; group $\mathrm{B}, 82 \%$, $\mathrm{p}<0.0001$; group C, $194 \%, \mathrm{p}<0.0001$; group $\mathrm{D}, 117 \%$, $\mathrm{p}<0.0001)$. In all groups TPO levels remained elevated throughout the treatment ( $\mathrm{p}<0.05$ for any week of therapy). After discontinuation of therapy, TPO levels returned to baseline within four weeks in group A and within 24 weeks in group B, while in groups C and D TPO levels were still 


\begin{tabular}{|c|c|c|c|c|c|c|c|}
\hline Parameter & Day 0 (pre-IFN) & Week 4 & Week 8 & Week 12 & End of therapy & $\begin{array}{l}\text { Week } 4 \text { after } \\
\text { therapy }\end{array}$ & $\begin{array}{l}\text { Week } 24 \text { after } \\
\text { therapy }\end{array}$ \\
\hline \multicolumn{8}{|c|}{ Haemoglobin (mg/dl) } \\
\hline Group A & $15(11.4-17.5)$ & $14.8(12.5-16.8)$ & $15(11.6-16)$ & $14.7(12.1-17.5)$ & $14.7(9.2-18.7)$ & $15(10.4-16.7)$ & $14.4(11.2-16.7)$ \\
\hline Group B & 15.2 (11.9-17.4) & $13.7(10.4-16.2)$ & $12.4(9.7-15.9)$ & 11.95 (10.2-14.4) & $12.2(9.9-14.7)$ & $12.9(10.2-15.4)$ & $14.6(11.2-17.9)$ \\
\hline Group C & 15 (12.6-17.8) & $12.1(8.8-15.9)$ & $12.3(8.5-16.4)$ & $11.9(9-16.6)$ & $11.4(9-14.2)$ & $13.2(9-15.9)$ & $14.2(9.5-17.1)$ \\
\hline Group D & $15.3(12.7-18)$ & $12.7(9.9-17.6)$ & $12.2(9.4-16.3)$ & $12.3(9.6-16.3)$ & $11.6(10-16.3)$ & $14.1(11.4-16.3)$ & 14.1 (11.7-16.8) \\
\hline \multicolumn{8}{|c|}{$\mathrm{EPO}(\mathrm{mlU} / \mathrm{ml})$} \\
\hline Group A & $8.1(2.9-26.6)$ & $8.8(6.2-14.1)$ & $8.4(4.1-19.2)$ & $8(4.2-15.6)$ & $9.2(7-45.4)$ & $7.5(4-51.4)$ & $7.7(4-49.3)$ \\
\hline Group B & $5.4(0-55.5)$ & $11.8(2.5-100.7)$ & $19.4(2.5-65.2)$ & $22.3(0-92)$ & $24.7(0-158.1)$ & $19.9(2.7-70.1)$ & $7(0-46)$ \\
\hline Group C & $5.3(0-19.2)$ & $21.9(0-91.6)$ & $26.9(3.4-136.5)$ & $29.5(4.4-198.3)$ & $33.1(0-188.5)$ & $18.5(3.6-89.9)$ & $7.7(2.5-63.2)$ \\
\hline Group D & $5.8(2-51.7)$ & $20.8(7.5-82.9)$ & $23.3(11-87.5)$ & $25.6(6.8-126.9)$ & $28.9(9.5-200)$ & $8.3(3.7-42.6)$ & $6.9(3.1-12.3)$ \\
\hline \multicolumn{8}{|c|}{ Reticulocytes $\left(10^{3} / \mu \mathrm{l}\right)$} \\
\hline Group A & - & - & - & - & - & - & - \\
\hline Group B & 44.9 (22.4-133) & $58.3(23.2-204)$ & $91.5(28-188)$ & $84(28.5-179)$ & $74.4(26.6-149)$ & $66.9(21.6-191)$ & $49.1(30.7-142)$ \\
\hline Group C & 43.7 (19.3-77.5) & $67.8(24.8-273)$ & $56.4(21.5-171)$ & $50.8(20.4-236)$ & $42.5(19.3-169)$ & $36.9(13.7-92.9)$ & $49.9(17.1-86.4)$ \\
\hline Group D & $48(15.8-94.5)$ & 70.9 (31.3-152) & $67(26.5-158)$ & $63.1(32.2-169)$ & $55.7(14.5-127)$ & $32.7(15.7-58.9)$ & $35.9(19.4-73.3)$ \\
\hline \multicolumn{8}{|c|}{ Platelets $\left(10^{3} / \mu \mathrm{l}\right)$} \\
\hline Group A & $158(42-307)$ & $132.5(45-272)$ & $127(42-225)$ & $129(48-221)$ & $148(32-308)$ & $186(88-384)$ & $137(38-299)$ \\
\hline Group B & $177(50-371)$ & $161(91-294)$ & $162.5(103-300)$ & $161(108-362)$ & $172(116-424)$ & $177(111-377)$ & 199 (131-299) \\
\hline Group C & $194(105-277)$ & $136.5(75-475)$ & $124(74-258)$ & $129.5(73-275)$ & $136(80-259)$ & $172(73-275)$ & $183(128-350)$ \\
\hline Group D & $188.5(86-343)$ & $155(80-290)$ & $148(86-256)$ & $140(72-306)$ & $153(65-259)$ & $210(64-421)$ & $198(120-438)$ \\
\hline \multicolumn{8}{|l|}{ TPO (pg/ml) } \\
\hline Group A & $95.2(60.2-166.1)$ & $134.9(59.3-217)$ & $131.4(81.6-240)$ & 135 (46.6-295.1) & $182.7(103.1-366.5)$ & 136.5 (75.3-219) & $134.4(83.8-203.8)$ \\
\hline Group B & $80.5(0-211.6)$ & $98.6(51.2-299.1)$ & $117.7(41.7-308.8)$ & $139.8(74.7-278.1)$ & 160.7 (36.1-334.8) & $148(52.3-362.1)$ & 83.1 (31.2-215.3) \\
\hline Group C & $72.4(0-156.2)$ & $95.1(0-246.6)$ & $130.2(0-381.1)$ & $151.1(50.1-355.9)$ & 170.1 & $136.9(53.9-362.4)$ & $87.3(38.4-174.8)$ \\
\hline Group D & $67.8(40.6-157.3)$ & $115.7(52.7-184.7)$ & 107.7 (67.9-214.7) & $155.5(64.4-300.8)$ & 165.1 (75.1-392) & $131.4(37.3-335.8)$ & $106.7(50.9-162.2)$ \\
\hline \multicolumn{8}{|c|}{ Leucocytes $\left(10^{3} / \mu \mathrm{l}\right)$} \\
\hline Group A & $6.7(3.5-10.5)$ & 5.4 (1.9-7.8) & $5(2.2-6.7)$ & $4.6(1.7-7.5)$ & $3.7(1.9-9)$ & $6.1(3.1-8.2)$ & $5.6(2.6-12.4)$ \\
\hline Group B & $5.5(3.2-10.8)$ & $3.9(1.3-10)$ & $3.4(2-8.2)$ & $3.4(2.1-6.8)$ & $3.3(2.1-7.4)$ & $3.6(2.3-6.4)$ & $6.1(2.8-10.2)$ \\
\hline Group C & $5.9(3.5-12.1)$ & $2.8(1.3-7.1)$ & $2.7(1.6-7.8)$ & $2.7(1.2-6.3)$ & $2.5(1.6-4.8)$ & $4.3(2.3-9.8)$ & $5.3(3.3-9.6)$ \\
\hline Group D & $6.5(3.8-12.3)$ & $3.5(1.9-5.9)$ & $3.4(2-5.1)$ & $3.1(1.7-7)$ & $3.2(1.8-7.1)$ & $5.2(1.9-13.2)$ & $6(4.2-10.1)$ \\
\hline
\end{tabular}

Values are medians (ranges).

Values in bold typeface indicate significant difference from pre-IFN treatment values ( $p<0.05$, Wilcoxon matched pairs test).

IFN, interferon; EPO, erythropoietin; TPO, thrombopoietin.

elevated at the end of follow up (group C, 43\%; group D, $47 \%$ above baseline at week 24 after the end of therapy) (fig 2, table 3 ), even though platelet counts had returned to normal.
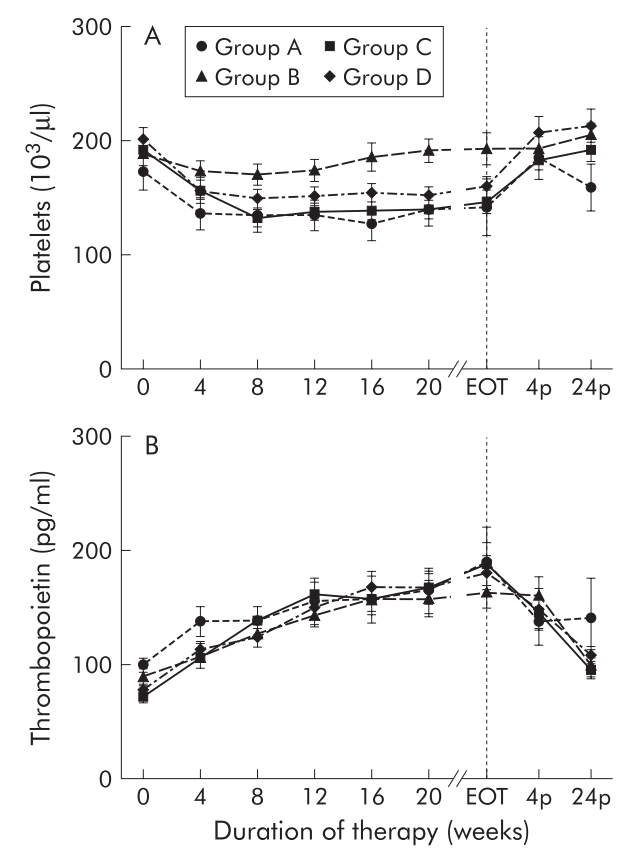

Figure 2 Thrombopoiesis. Platelet (A) and thrombopoietin (B) levels before (week 0), during (week 4 until the end of therapy (EOT)) and after (week $4 \mathrm{p}$ and week $24 \mathrm{p}$ ) therapy with conventional interferon $\alpha$ (IFN- $\alpha$ ) alone (group A), in combination with ribavirin (group B), with pegylated IFN- $\alpha 2$ a (group $C$ ), or with pegylated IFN- $\alpha 2 b$ in combination with ribavirin (group D). Data are mean (SEM).
At baseline and week 4, patients in group A had higher TPO levels than those in group $\mathrm{C}(\mathrm{p}<0.05)$. Later on, throughout the whole treatment period, TPO levels were comparable between all four groups (Mann-Whitney U test, NS) (fig 2). In group A, PPC was lower in patients with liver cirrhosis compared with patients without cirrhosis (Mann-Whitney U test: $\mathrm{p}<0.05$ for week 0 to week 24) but TPO levels did not differ. In patients in group B, C, and D, the effects of IFN on thrombopoiesis were comparable between those with or without liver cirrhosis.

\section{White blood count during IFN therapy}

White blood count (WBC) was decreased in all groups after four weeks of therapy (median decrease in group A, 26\%; group B, 31\%; group C, 50\%, group D, $44 \%$; $p<0.05$ for group A, $p<0.0001$ for groups $\mathrm{B}, \mathrm{C}$, and D) and remained decreased throughout treatment (group $\mathrm{A}, \mathrm{p}<0.05$; groups $\mathrm{B}, \mathrm{C}$, and $\mathrm{D}$, $\mathrm{p}<0.0001$ for any week of therapy), with a maximum drop of $37 \%$ in group A at the end of therapy, 39\% in group B at week $16,55 \%$ in group $C$ at the end of therapy, and $52 \%$ in group D at week 12. After termination of treatment, WBC returned to baseline within 24 weeks in all treatment groups (fig 3, table 3). The decrease in WBC levels was more severe in patients in group $\mathrm{C}$ than in those in groups $\mathrm{A}, \mathrm{B}$, and $\mathrm{D}$ (group A $v$ group $\mathrm{C}$ and group $\mathrm{B} v$ group $\mathrm{C}, \mathrm{p}<0.01$ at any week of therapy; group C $v$ group $\mathrm{D}, \mathrm{p}<0.05$ at weeks 4,8 , and end of therapy), and in patients in group D compared with those in group A (group A $v$ group D, $<<0.01$ at week 4 to week 20). Patients in groups A and B and those in groups B and D showed comparable decreases in WBC levels (group A $v$ group B, p $<0.05$ at week 8 and 12, NS at any other week of therapy; group B $v$ group $\mathrm{D}, \mathrm{p}<0.05$ at week 20 , NS at any other week of therapy) (fig 3 ).

The decrease in WBC affected both neutrophils and lymphocytes. At week 4 of therapy, levels of both cell types 

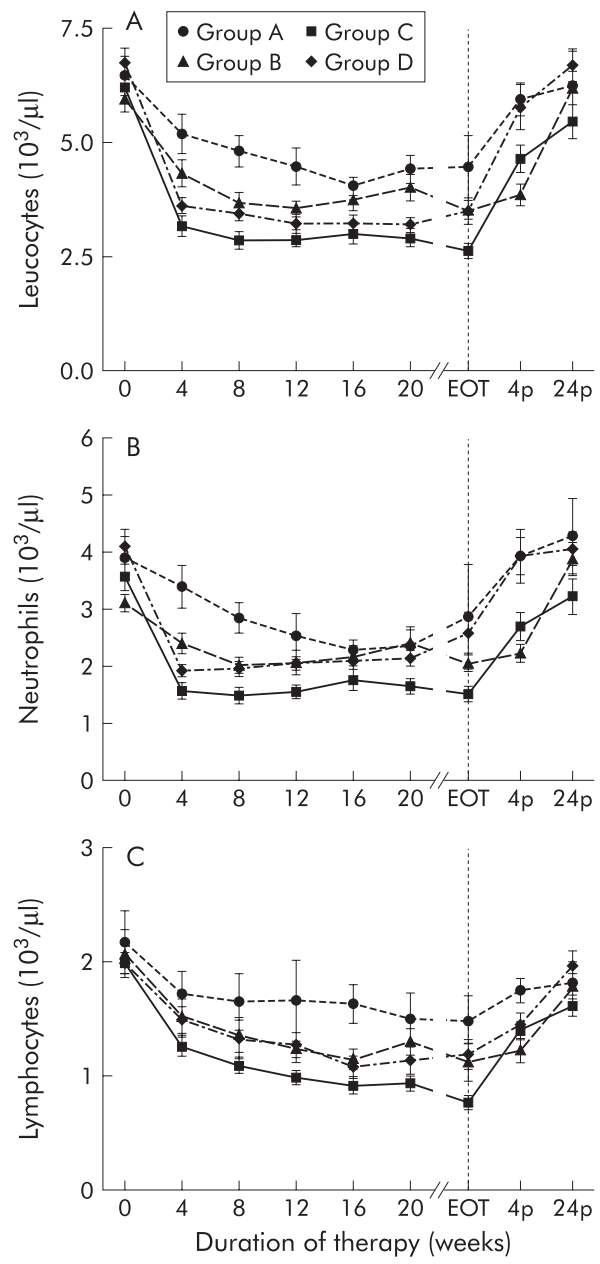

Figure 3 Leucopoiesis. Leucocyte count (A), neutrophil count (B), and lymphocyte count (C) before (week 0), during (week 4 until the end of therapy (EOT)) and after (week $4 p$ and week 24p) therapy with conventional interferon $\alpha$ (IFN- $\alpha$ ) alone (group $A)$, in combination with ribavirin (group B), with pegylated IFN- $\alpha 2$ a (group C), or with pegylated IFN- $\alpha 2 b$ in combination with ribavirin (group D). Data are mean (SEM).

decreased in patients on combination therapy (median decrease in neutrophils in group B, 40\%; group C, 56\%; group D, 55\%; lymphocytes, group B, $14 \%$; group C, $35 \%$; group D, 27\%; $<<0.0001$ ). The decrease in neutrophils and lymphocytes in patients in group A was only marginal (median decrease in neutrophils 22\%, lymphocytes 9\%; Wilcoxon matched pairs test, NS) (fig 3). In patients on combination therapy both neutrophils and lymphocytes remained decreased throughout treatment. Groups B, C, and $\mathrm{D}$ reached the nadir of neutrophil count at week 8 (median decrease in group B, $40 \%$; group C, $55 \%$; group D, $49 \%$ ) while lymphocytes continued to decrease and reached their nadir at week 16 in group D and at the end of treatment in groups B and C (median decrease in group B, 53\%; group C, 62\%; group D, 50\%) (fig 3). After the end of treatment, neutrophil counts returned to baseline levels within four weeks in group D and within 24 weeks in groups B and C. Lymphocyte counts returned to baseline levels within 24 weeks after the end of treatment in groups B and D but remained below baseline levels in patients in group $\mathrm{C}$ at the end of follow up (median 12\% below baseline at week 24 after therapy) (fig 3). However, the increase in lymphocyte counts in group $\mathrm{C}$ from the end of treatment until the end of follow up was significantly higher than in the other groups (median increase in group A, 32\%; group B, $80 \%$; group C, $128 \%$; group D, $72 \%$; $<<0.05$ )

The decrease in neutrophil counts was comparable between groups $\mathrm{A}, \mathrm{B}$, and $\mathrm{D}$, showing significant differences only at the beginning of therapy (group A $v$ group B, group A $v$ group $\mathrm{D}, \mathrm{p}<0.05$ for weeks 4 and 8 , NS for any other week of treatment; group B $v$ group D, NS for any week of therapy). Compared with groups A, B, and D, neutrophil count was lower in group $\mathrm{C}$ throughout the whole therapy (group $\mathrm{A} v$ group $\mathrm{C}$, group B $v$ group $\mathrm{C}$, group $\mathrm{C} v$ group $\mathrm{D}, \mathrm{p}<0.01$ for any week of therapy) (fig 3 ). The decrease in lymphocyte count was comparable between groups A, B, and D (group A $v$ group B, group A $v$ group $\mathrm{D}, \mathrm{p}<0.05$ at week 16 of therapy, NS at any other week of therapy; group B $v$ group D, NS for any week of therapy) but was significantly lower in group $\mathrm{C}$ than in groups A, B, and D (group A $v$ group C, $<<0.05$ at any week of therapy; group B $v$ group $\mathrm{C}, \mathrm{p}<0.05$ at week 16 until the end of therapy; group $\mathrm{C} v$ group $\mathrm{D}, \mathrm{p}<0.05$ at week 4 , week 24, and at the end of therapy, NS at any other week of therapy) (fig 3). IFN therapy did not affect leucopoiesis differently in patients with liver cirrhosis compared with those without cirrhosis (NS).

\section{DISCUSSION}

Administration of both standard or pegylated IFN- $\alpha$ alone or in combination with ribavirin causes a significant decrease in all three lineages of the haematopoietic system, which cannot be completely counteracted by the endogenous production of haematopoietic growth factors. ${ }^{8}{ }^{16} 32$ The mechanisms responsible for induction of cytopenia during IFN therapy have been studied in detail in vitro. Direct inhibition of progenitor cell proliferation in the bone marrow seems to be the dominant factor. ${ }^{19} 2033$ In this study the effect of four treatment regimens on haematopoiesis was distinct. Haemoglobin levels were significantly diminished only in those patients receiving combination therapy with ribavirin, which accumulates in red blood cells and causes alterations in the erythrocyte membrane known to be associated with erythrophagocytic extravascular destruction and haemolysis. ${ }^{723}$

Although reticulocytes increased significantly in all groups receiving combination therapy, the increase was inadequate to overcome the effects of IFN/ribavirin combination therapy, despite significantly elevated EPO levels. This confirms the suppressive action of IFN- $\alpha$ on erythroid progenitor cell proliferation. ${ }^{1019}{ }^{20}$ Long acting peginterferons appear to exert a more pronounced suppressive effect as reticulocytes were significantly higher despite less pronounced anaemia and similar EPO levels in patients treated with the conventional IFN/ribavirin (group B) compared with groups C and D. In patients who received pegylated IFN, haemoglobin levels had not returned to baseline at the end of the study period while in those in group B, haemoglobin values reached baseline 24 weeks after the end of therapy.

Possibly the most interesting clinically relevant question is whether the side effects of the different regimens require dose modifications during therapy with direct impact on clinical outcome such as sustained viral response. While this study clearly does not have the power to answer this question, there are some clues which will need to be pursued in larger analyses: even though no direct differences between the two pegylated IFNs could be demonstrated with regard to decrease in haemoglobin levels, ribavirin dose reductions, or patients who received less than $80 \%$ of the scheduled dose, there where significantly more patients who received $40 \mathrm{kDa}-$ PegIFN- $\alpha 2$ a (group C) who had a haemoglobin level $<10$ g/dl and who received $<80 \%$ of their scheduled dose compared with the conventional IFN/ribavirin group (group B). No difference between group B and group D was observed for these parameters. 
In all treatment groups the endogenous physiological increase in EPO was unable to counteract the adverse effects of IFN/RBV. Correction of anaemia could result in better adherence to combination therapy, which may lead to improved sustained virological response rates. Potential strategies include treatment with antiviral agents that do not cause significant haemolysis, such as levovirin or viramidine, or support with haematopoietic growth factors. Recent data show that treatment with superphysiological doses of recombinant EPO can positively impact erythropoiesis, by correcting anaemia and thereby permitting maintenance of patients' intended ribavirin dose. ${ }^{34-38}$

PPC was significantly reduced in all groups after four weeks of treatment. The significant increase in TPO levels paralleling the decrease in platelet count indicates a true reduction in platelet number, because TPO is produced at a constant rate and regulated through clearance by c-mpl receptors on platelets and megakaryocytes. ${ }^{39}{ }^{40}$ The decrease in PPC by IFN- $\alpha$ is caused by diminished production of platelets through suppression of megakaryocyte progenitor cell proliferation and differentiation in bone marrow, ${ }^{9}{ }^{10}$ as shown previously. The median increase in TPO levels (48$117 \%$ ) was not as high as one would expect, considering the exponential increase in TPO levels with declining platelet count, ${ }^{41}$ and seems to confirm previous findings of a blunted TPO response to thrombocytopenia during IFN therapy. ${ }^{32}$

The inability of increased TPO serum levels to sufficiently counteract the decrease in platelet production could also be explained by induction of suppressor of cytokine signalling 1 (SOCS-1) by IFN- $\alpha .9^{92}$ Irrespective of the underlying mechanism, the increase in endogenous TPO was insufficient to counteract the impact of therapy in groups A, C, and D. Combination therapy with ribavirin did not cause a further decrease in PPC, as previously described, ${ }^{5}$ and PPCs even increased after an initial drop in patients receiving standard IFN combined with ribavirin (group B). The mechanism seems to be the combined effects of elevated TPO and EPO levels on megakaryocytic progenitor cell proliferation. ${ }^{434}$ EPO levels were significantly higher during combination therapy with ribavirin compared with IFN monotherapy because of the stimulus triggered by haemolytic anaemia. ${ }^{45}$ However, in patients receiving pegylated IFN and ribavirin, the combined effects of high TPO and EPO serum levels were not able to overcome the suppressive action of pegIFN on thrombopoiesis. This is likely because of a stronger and continuous suppressive effect of pegylated IFN on progenitor cell proliferation compared with standard IFN. Again, as shown for erythropoiesis, pegylated IFN- $\alpha 2$ a seems to exert a slightly stronger suppressive effect on thrombopoiesis compared with pegylated IFN- $\alpha 2 \mathrm{~b}$.

The two groups treated with long acting peginterferons did not differ with regard to their PPC levels but did differ compared with the conventional IFN/ribavirin group B. Leucocytes decreased and remained below baseline levels throughout the whole treatment period in all groups (fig 3). The decrease in WBC in the monotherapy group was only marginal. Both pegylated IFNs exerted a stronger suppressive effect on leucopoiesis compared with monotherapy with conventional IFN, but compared with group B, only group C showed a significantly stronger suppression of WBC. When the two peg-IFNs were directly compared, patients treated with IFN- $\alpha 2$ a showed lower WBC counts at weeks 4 and 8 , and at the end of therapy.

Neutrophil and lymphocyte counts were the only parameters with a clearcut statistically significant difference between the two peginterferon preparations. Throughout the whole of the treatment period, patients in group $C$ had significantly lower levels of neutrophils compared with patients in group D. The difference in lymphocyte counts between the two groups could only be seen at week 4, at the end of therapy, and at the end of follow up. While the difference at the end of therapy can be explained by the difference in treatment duration between these groups, the difference in WBC and lymphocyte counts at the beginning of therapy and neutrophil counts throughout the treatment period could be attributed to different pharmacological properties. Whether this is due to different biological properties of the modified interferon molecules or an effect of dose accumulation of the $40 \mathrm{kDa}-\mathrm{PegIFN}-\alpha 2 \mathrm{a}$ compared with the $12 \mathrm{kDa}-\mathrm{PegIFN}-\alpha 2 \mathrm{~b}$ cannot be determined with certainty. The fact that despite similar antiviral activities there was a clearcut difference in leucopoiesis and a similar trend in erythropoiesis and thrombopoiesis in favour of the $12 \mathrm{kDa}-\mathrm{PegIFN}-\alpha 2 \mathrm{~b}$ still provides no clear mechanistic distinction but argues in favour of at least some biological differences between these drugs.

Another interesting fact is that only in patients in group C did lymphocytes not return to baseline levels at the end of the study period. Most likely this can be explained by the longer duration of therapy in this group. An irreversible effect of pegIFN- $\alpha 2 \mathrm{a}$ is unlikely as patients in group $\mathrm{C}$ showed the highest increase in lymphocyte counts from the end to therapy until the end of follow up, and as lymphocyte counts were within the normal range at the end of the study period the clinical relevance of this observation is questionable.

In summary, the haematological toxic effects of combination antiviral therapy with IFN/ribavirin occur in association with a marked increase in endogenous growth factor levels of EPO and TPO. Yet these marked increases are still insufficient to counteract the side effects to an extent that would allow all patients to receive full dose antiviral therapy.

There is evidence that patients with marked haematological toxicities will benefit from treatment with superphysiological doses of specific haematopoietic growth factors, ${ }^{7} 3538$ 46-48 enabling them to receive full dose combination therapy. Whether this can ultimately improve sustained virological response rates remains to be established in prospective randomised trials. These trials should provide the answer to the important question of whether expensive growth factor therapy in addition to full dose antiviral therapy will become an accepted and worthwhile alternative to dose reduction of antiviral therapy.

\section{Authors' affiliations}

M Schmid, A Kreil, W Jessner, M Homoncik, A Gangl, P Ferenci, M Peck-Radosavljevic, Department Internal Medicine IV, Division of Gastroenterology and Hepatology, University of Vienna, Vienna, Austria C Datz, Department of Internal Medicine, KH Oberndorf, Salzburg, Austria

Conflict of interest: None declared.

\section{REFERENCES}

1 Di Bisceglie AM, Goodman ZD, Ishak KG, et al. Long-term clinical and histopathological follow-up of chronic posttransfusion hepatitis. Hepatology 1991;14:969-74.

2 Tong MJ, el-Farra NS, Reikes AR, et al. Clinical outcomes after transfusionassociated hepatitis C. N Engl J Med 1995;332:1463-6.

3 Fattovich G, Giustina G, Degos F, et al. Morbidity and mortality in compensated cirrhosis type C: a retrospective follow-up study of 384 patients. Gastroenterology 1997; 112:463-72.

4 Davis GL, Esteban-Mur R, Rustgi V, et al. Interferon alfa-2b alone or in combination with ribavirin for the treatment of relapse of chronic hepatitis $C$. International Hepatitis Interventional Therapy Group. N Engl J Med 1998;339:1493-9.

5 McHutchison JG, Gordon SC, Schiff ER, et al. Interferon alfa-2b alone or in combination with ribavirin as initial treatment for chronic hepatitis $C$. Hepatitis Interventional Therapy Group. N Engl J Med 1998;339:1485-92.

6 Russo MW, Fried MW. Side effects of therapy for chronic hepatitis C. Gastroenterology 2003;124:1711-19.

7 Fried MW. Side effects of therapy of hepatitis $C$ and their management. Hepatology 2002;36(suppl 1):S237-44. 
8 Peck-Radosavlievic M, Wichlas M, Homoncik-Kraml M, et al. Rapid suppression of haematopoiesis by standard or pegylated interferon-alpha. Gastroenterology 2002;123:141-51.

9 Wang Q, Miyakawa $\mathrm{Y}$, Fox $\mathrm{N}$, et al. Interferon-alpha directly represses megakaryopoiesis by inhibiting thrombopoietin-induced signaling through induction of SOCS-1. Blood 2000;96:2093-9

10 Lengfelder $E$, Berger $U$, Hehlmann R. Interferon alpha in the treatment of polycythemia vera. Ann Hematol 2000;79:103-9.

11 Fattovich G, Giustina G, Favarato S, et al. A survey of adverse events in 11,241 patients with chronic viral hepatitis treated with alfa interferon. J Hepatol 1996;24:38-47.

12 Bodenheimer HC Jr, Lindsay KL, Davis GL, et al. Tolerance and efficacy of oral ribavirin treatment of chronic hepatitis C: a multicenter trial. Hepatology 1997;26:473-7.

13 Dusheiko G, Main J, Thomas $\mathrm{H}$, et al. Ribavirin treatment for patients with chronic hepatitis C: results of a placebo-controlled study. J Hepatol 1996:25:591-8.

14 Shrestha R, McKinley C, Bilir BM, et al. Possible idiopathic thrombocytopenic purpura associated with natural alpha interferon therapy for chronic hepatitis C infection. Am J Gastroenterol 1995;90:1146-7.

15 Lopez Morante AJ, Saez-Royuela F, Casanova Valero F, et al. Immune thrombocytopenia after alpha-interferon therapy in a patient with chronic hepatitis C. Am J Gastroenterol 1992;87:809-10.

16 Pardo M, Marriott E, Moliner MC, et al. Risks and benefits of interferon-alpha in the treatment of hepatitis. Drug Saf 1995;13:304-16.

17 Wong S, Kaita K, Gauthier T, et al. A comparative trial of recombinant interferon alpha $2 \mathrm{~A}$ versus alpha 2 beta on myelosuppression in healthy adult volunteers. Hepatogastroenterology 1996;43:301-5.

18 Soza A, Everhart JE, Ghany MG, et al. Neutropenia during combination therapy of interferon alfa and ribavirin for chronic hepatitis C. Hepatology 2002;36:1273-9.

19 Ernstoff MS, Kirkwood JM. Changes in the bone marrow of cancer patients treated with recombinant interferon alpha-2. Am J Med 1984;76:593-6.

20 Ganser A, Carlo-Stella C, Greher J, et al. Effect of recombinant interferons alpha and gamma on human bone marrow-derived megakaryocytic progenitor cells. Blood 1987;70:1173-9.

21 Hoofnagle JH. Thrombocytopenia during interferon alfa therapy. JAMA 1991;266:849

22 Dormann H, Krebs S, Muth-Selbach U, et al. Rapid onset of hematotoxic effects after interferon alpha in hepatitis C. J Hepatol 2000;32:1041-2.

23 De Franceschi L, Fattovich G, Turrini F, et al. Hemolytic anemia induced by ribavirin therapy in patients with chronic hepatitis $C$ virus infection: role of membrane oxidative damage. Hepatology 2000;31:997-1004.

24 Manns MP, McHutchison JG, Gordon SC, et al. Peginterferon alfa-2b plus ribavirin compared with interferon alfa- $2 b$ plus ribavirin for initial treatment of chronic hepatitis C: a randomised trial. Lancet 2001;358:958-65.

25 Ferenci $P$, Stauber R, Steindl-Munda $P$, et al. Treatment of patients with chronic hepatitis $C$ not responding to interferon with high-dose interferon alpha with or without ribavirin: final results of a prospective randomized trial. Austrian Hepatitis Study Group. Eur J Gastroenterol Hepatol 2001; 13:699-705.

26 Ferenci $\mathbf{P}$, Brunner $\mathrm{H}$, Nachbaur $\mathrm{K}$, et al Combination of interferon induction therapy and ribavirin in chronic hepatitis C. Hepatology 2001;34:1006-11.

27 Fried MW, Shiffman ML, Reddy KR, et al. Peginterferon alfa-2a plus ribavirin for chronic hepatitis C virus infection. N Engl J Med 2002;347:975-82.

28 Hofmann H, Glitzner M, Schindlegger S. Incidence of hepatitis $C$ virus genotypes in Austria. Wien Klin Wochenschr 1995;107:340-3.

29 Ludwig J. A review of lobular, portal, and periportal hepatitis. Interpretation of biopsy specimens without clinical data. Hum Pathol 1977;8:269-76.
30 Robert A, Chazouilleres O. Prothrombin time in liver failure: time, ratio, activity percentage, or international normalized ratio? Hepatology 1996;24:1392-4

31 Peck-Radosavljevic M, Wichlas M, Zacherl J, et al. Thrombopoietin induces rapid resolution of thrombocytopenia after orthotopic liver transplantation through increased platelet production. Blood 2000;95:795-801.

32 Peck-Radosavlievic M, Wichlas M, Pidlich J, et al. Blunted thrombopoietin response to interferon alfa-induced thrombocytopenia during treatment for hepatitis C. Hepatology 1998;28:1424-9.

33 Hoofnagle JH, di Bisceglie AM. The treatment of chronic viral hepatitis. N Engl J Med 1997;336:347-56.

34 Dieterich DT, Pockros PJ, Schiff ER, et al. Epoetin Alpha (Procrit) once weekly maintains ribavirin dose in hepatitis $C$ virus (HCV)-infected patients treated with combination therapy: interim results of a randomized, double-blind, placebo-controlled study (abstr.). Hepatology 2002;36:286A.

35 Dieterich DT, Wasserman R, Brau N, et al. Once-weekly epoetin alfa improves anemia and facilitates maintenance of ribavirin dosing in hepatitis $C$ virusinfected patients receiving ribavirin plus interferon alfa. Am J Gastroenterol 2003:98:2491-9.

36 Dieterich DT, Wassermann R, Brau N, et al. Once-weekly recombinant human erythropoietin (Epoetin Alpha) facilitates optimal ribavirin (RBV) dosing in hepatitis C (HCV)-infected patients receiving IFN-alpha-2b (IFN)/RBV combination therapy. Gastroenterology 2001;120:340.

37 Wasserman R, Brau N, Haasnein TI, et al. Once weekly Epoetin alpha increases hemoglobin and decreases RBV discontinuation among HCV patients who develop anemia on RBV/INF therapy. Hepatology 2000;32:A368

38 Afdahl NH, Dieterich DT, Pockros PJ, et al. Epoetin alfa treatment of anemic $\mathrm{HCV}$-infected patients allows for maintenance of ribavirin dose, increases hemoglobin levels, and improves quality of life vs placebo: a randomized, double-blind, multicenter study. Gastroenterology 2003;124(suppl 1):A714

39 Fielder PJ, Gurney AL, Stefanich E, et al. Regulation of thrombopoietin levels by c-mpl-mediated binding to platelets. Blood 1996:87:2154-61.

40 Jelkmann W. The role of the liver in the production of thrombopoietin compared with erythropoietin. Eur J Gastroenterol Hepatol $2001 ; 13: 791-801$

41 Kuter DJ. The regulation of platelet production in vivo. In:Kuter DJ, Hunt $P$, Sheridan W, et al. Thrombopoiesis and thrombopoietins: molecular, cellular, preclinical, and clinical biology. Clifton, NJ: Humana Press, 1997:377-95.

42 Weidekamm C, Wichlas M, Kreil A, et al. Thrombopoietin (TPO) antagonizes the antiproliferative action of IFN-alpha on megakaryocytic cell lines. J Hepatol 2000;30(suppl 1):178.

43 Stohlawetz PJ, Dzirlo L, Hergovich N, et al. Effects of erythropoietin on platelet reactivity and thrombopoiesis in humans. Blood 2000;95:2983-9.

44 Broudy VC, Lin NL, Kaushansky K. Thrombopoietin (c-mpl ligand) acts synergistically with erythropoietin, stem cell factor, and interleukin-11 to enhance murine megakaryocyte colony growth and increases megakaryocyte ploidy in vitro. Blood 1995:85:1719-26.

45 Peck-Radosavljevic M, Kreil A, Hofer H, et al. Increased thrombopoietin and erythropoietin serum levels and recovery of platelet counts during IFNribavirin combination therapy. Hepatology 1999;30:261A.

46 Burroughs AK. Posttransplantation prevention and treatment of recurrent hepatitis C. Liver Transp/ 2000;6(suppl 2):S35-40

47 Gopal DV, Rabkin JM, Berk BS, et al. Treatment of progressive hepatitis C recurrence after liver transplantation with combination interferon plus ribavirin. Liver Transp/ 2001;7:181-90.

48 Golia $\mathbf{P}$, Talal AH, Jacobson IM, et al. A preliminary study of growth factor versus dose reduction for peg interferon alfa- $2 \mathrm{~b}$ and ribavirin associated neutropenia and anemia in HIV/HCV co-infected patients. Gastroenterology 2003; 124(suppl 1):A766. 